\title{
Cerebellar Vermis Involvement in Cocaine-Related Behaviors
}

\author{
Carl M Anderson', Luis C Maas', Blaise deB Frederick', Jacob T Bendor², Thomas J Spencer ${ }^{3}$, Eli Livni ${ }^{3}$, \\ Scott E Lukas ${ }^{4}$, Alan J Fischman ${ }^{3}$, Bertha K Madras ${ }^{2}$, Perry F Renshaw' and Marc J Kaufman*,' \\ 'Brain Imaging Center, McLean Hospital, Harvard Medical School, Belmont, MA, USA; ²Department of Psychiatry, Division of Neurochemistry, \\ New England Primate Research Center, Harvard Medical School, Southborough, MA, USA; ${ }^{3}$ Division of Nuclear Medicine of the Department of \\ Radiology, Massachusetts General Hospital, Boston, MA, USA; ${ }^{4}$ Behavioral Psychopharmacology Research Laboratory, Department of Psychiatry, \\ McLean Hospital, Harvard Medical School, Belmont, MA, USA
}

\begin{abstract}
Although the cerebellum is increasingly being viewed as a brain area involved in cognition, it typically is excluded from circuitry considered to mediate stimulant-associated behaviors since it is low in dopamine. Yet, the primate cerebellar vermis (lobules II-III and VIII-IX) has been reported to contain axonal dopamine transporter immunoreactivity (DAT-IR). We hypothesized that DAT-IR-containing vermis areas would be activated in cocaine abusers by cocaine-related cues and, in healthy humans, would accumulate DAT-selective ligands. We used BOLD FMRI to determine whether cocaine-related cues activated DAT-IR-enriched vermis regions in cocaine abusers and positron emission tomography imaging of healthy humans to determine whether the DAT-selective ligand $\left[{ }^{\prime \prime} \mathrm{C}\right]$ altropane accumulated in those vermis regions. Cocaine-related cues selectively induced BOLD activation in lobules II-III and VIII-IX in cocaine users, and, at early time points after ligand administration, we found appreciable [ ' $\mathrm{C}$ ]altropane accumulation in lobules VIII-IX, possibly indicating DAT presence in this region. These data suggest that parts of cerebellar vermis mediate cocaine's persisting and acute effects. In light of prior findings illustrating vermis connections to midbrain dopamine cell body regions, established roles for the vermis as a locus of sensorimotor integration and motor planning, and findings of increased vermis activation in substance abusers during reward-related and other cognitive tasks, we propose that the vermis be considered one of the structures involved in cocaine- and other incentive-related behaviors.
\end{abstract}

Neuropsychopharmacology (2006) 3 I, 1318-1326. doi:I0.1038/sj.npp. I 300937; publication online 12 October 2005

Keywords: cocaine; stimulants; cerebellum; vermis; dopamine transporter; craving

\section{INTRODUCTION}

A common circuitry has been proposed to regulate drugseeking behaviors evoked by stimulant drugs, their cues, and stress (Kalivas and McFarland, 2003). The circuitry includes a 'limbic subcircuit' (ventral tegmental area, amygdala/extended amygdala, mediodorsal thalamus, and lateral tegmental nucleus) that channels information into a 'motor subcircuit' (dorsal prefrontal cortex/anterior cingulate and nucleus accumbens core) referred to as a 'final common pathway' linking cognitive processing to behavioral output (Kalivas and McFarland, 2003). Most, but not all structures comprising these circuits exhibit relatively high concentrations of dopamine and dopamine transporters (DAT), the latter of which is blocked by cocaine and other stimulants, leading to the rapid synaptic dopamine

\footnotetext{
*Correspondence: Dr MJ Kaufman, Brain Imaging Center, McLean Hospital, I I 5 Mill Street, Belmont, MA 02478, USA, Tel: + I 617855 3469, Fax: + | 617855 2770, E-mail: kaufman@mclean.harvard.edu Received 21 March 2005; revised 25 July 2005; accepted 2 September 2005

Online publication: 13 September 2005 at http://www.acnp.org/ citations/Npp09|305050193/default.pdf
}

increases thought to contribute to the acute behavioral effects of cocaine and other abused drugs.

Yet, a number of brain structures with relatively low dopamine and DAT levels appear to mediate effects of cocaine and other stimulants. One such region is the frontal cortex, which is intimately connected with the circuitry described above but is low in dopamine and DAT. By virtue of its involvement in salience attribution and in regulating inhibition of inappropriate behavioral responses, the frontal cortex appears to act as a higher order locus of control over stimulant and other drug-seeking behaviors (for review, see Goldstein and Volkow, 2002). Another brain area, the cerebellum, has been proposed to play a role in reinforcement (Martin-Solch et al, 2001). The cerebellum, like the frontal cortex, has relatively low concentrations of dopamine and dopamine receptors, and whole cerebellar DAT binding is very low (Kaufman et al, 1991; Fischman et al, 2001). Thus, it typically is excluded from consideration as a region mediating drug-associated behaviors. However, as has been noted by Cotterill (2001), 'Muscular contraction is the nervous system's only externally directed product, and the signaling routes which pass through the various brain components must ultimately converge on the motor areas' 
(Cotterill, 2001). Indeed, recent data suggest that the cerebellum plays fundamental roles in a number of cognitive processes required for executing goal-directed and suppressing disadvantageous behaviors, including sensory functions (Paradiso et al, 1999), attention (Allen et al, 1997; Bischoff-Grethe et al, 2002), conditioned response learning (Logan and Grafton, 1995), and executive functions (Smith and Jonides, 1997; Ernst et al, 2003; Hülsmann et al, 2003) including response inhibition (Mostofsky et al, 2003). Thus, the cerebellum is critically interposed to link internal processing of exteroceptive and interoceptive stimuli to action.

A cerebellar role in stimulant-associated behaviors is suggested by several functional imaging studies. Cerebellar activation in response to presentation of cues for cocaine initially was reported by Grant et al (1996) who noted a correlation between cerebellar activation and degree of cocaine craving. Subsequent studies noted cerebellar activity during cocaine craving (Kilts et al, 2001; Bonson et al, 2002), during recall or imagery of cocaine-use experiences (Wang et al, 1999; Kilts et al, 2001), and during stimulant expectancy (Volkow et al, 2003). Acute administration of or cues for other stimulants or psychoactive drugs also has been associated with increased cerebellar activity (Volkow et al, 1996, 1988; London et al, 1990; Ghatan et al, 1998; Sell et al, 1999; Domino et al, 2000). Two studies reported cerebellar midline (vermis) activation by alcohol odor cues and by stimulant expectancy (Schneider et al, 2001; Volkow et al, 2003). Such findings are intriguing in light of reports localizing DAT immunoreactivity (DAT-IR) and mRNA in primate cerebellar vermis (Melchitzky and Lewis, 2000; Hurley et al, 2003). Moreover, in rodents, the vermis is a context-dependent self-stimulation site (Ball et al, 1974) and vermis lesions alter cortical dopamine turnover (Snider and Snider, 1977). Together, these findings suggest that the cerebellum and the vermis in particular may exert some regulatory control over forebrain dopamine neurotransmission.

To date, a role for the vermis in mediating effects of abused drugs has not been evaluated or articulated in detail. Accordingly, we used blood oxygen level-dependent functional MRI (BOLD fMRI) to assess whether presentation of cocaine-related audiovisual cues evokes vermis activation in cocaine abusers. We retrospectively analyzed fMRI data acquired as part of our previously published study noting cocaine cue-associated anterior cingulate and left dorsolateral prefrontal cortex activation (Maas et al, 1998). That study reported no significant BOLD effect in cerebellum (Maas et al, 1998). However, it was published prior to the vermis DAT-IR findings of Melchitzky and Lewis (2000) and cerebellum was analyzed as a whole structure, an approach that would have missed small activation areas due to partial volume effects. In our reanalysis, we hypothesized that we would observe selective cocaine cue-associated BOLD activation in vermis regions (lobules II-III and VIII-IX) reportedly containing axonal DAT-IR (Melchitzky and Lewis, 2000).

In addition, though DAT-IR and mRNA have been localized in vermis (Melchitzky and Lewis, 2000; Hurley et al, 2003), no study to date has directly characterized vermis DAT density or distribution. While we (Kaufman et al, 1991; Fischman et al, 2001) and others documented low whole cerebellar DAT-binding levels in vitro and in vivo, as noted above, global DAT-binding measurements might have missed DAT-enriched zones. Thus, we conducted an in vitro autoradiographic study in human post-mortem cerebellar vermis tissue sections and an in vivo positron emission tomography (PET) study of healthy human cerebellum, using the DAT-selective cocaine congeners $\left[{ }^{3} \mathrm{H}\right] 2 \beta$-carbomethoxy-3 $\beta$-(4-fluorophenyl) tropane $\left(\left[{ }^{3} \mathrm{H}\right] \mathrm{CFT}\right)$ (Kaufman et al, 1991) and $\left[{ }^{11} \mathrm{C}\right] 2 \beta$ carbomethoxy-3 $\beta$-(4-fluorophenyl)- $N$-(1-iodoprop-1-en-3-yl) nortropane ( $\left.{ }^{11} \mathrm{C}\right]$ altropane) (Fischman et al, 2001), respectively, to examine vermis ligand accumulation. We hypothesized that $\left[{ }^{3} \mathrm{H}\right] \mathrm{CFT}$ and $\left[{ }^{11} \mathrm{C}\right]$ altropane would accumulate selectively in vermis lobules II-III and VIII-IX.

\section{MATERIALS AND METHODS}

\section{BOLD fMRI}

We studied 10 crack cocaine abusers (six men) with $\geqslant 6$ month histories of at least biweekly crack abuse (mean (SD) age $=36 \pm 7$ years old), and eight comparison subjects (three men, $31 \pm 6$ years old). Crack cocaine was the preferred drug of abuse by cocaine subjects but history of other drug use was not grounds for exclusion. Comparison subjects reported no history of drug abuse of any form. Subjects were screened with the Structured Clinical Interview for DSM-IV Axis I Disorders. Subjects with histories of psychotic disorder or current Axis I mood disorder were excluded. All subjects were otherwise healthy and had no history of neurological disorder. All subjects tested negative for recent drug (Triage Test, Biosite Diagnostics Inc.) and alcohol (Alco Sensor III, Intoximeters Inc.) use immediately prior to the fMRI study.

Studies were conducted with approval from the McLean Hospital Institutional Review Board and subjects provided written informed consent. The cocaine cue audiovisual presentation consisted of four contiguous 150-s alternating segments of neutral (butterflies) and cocaine-related scenes and sounds (Childress et al, 1999) adapted for presentation to each subject via an MRI-compatible audiovisual system (Maas et al, 1998), while supine in the magnet.

All fMRI data were obtained on a 1.5 Tesla General Electric Signa scanner (Milwaukee, WI) retrofit with a whole body resonant gradient set (Advanced NMR Systems Inc., Wilmington, MA). Gradient echo planar images were acquired from 16 oblique-coronal slices, including four to five slices containing cerebellum, with the following parameters: $7-\mathrm{mm}$ thickness, $3-\mathrm{mm}$ skip, $\mathrm{TE}=40 \mathrm{~ms}$, $\mathrm{TR}=5 \mathrm{~s}, \alpha=90^{\circ}$, in-plane resolution $=3.125 \times 3.125 \mathrm{~mm}^{2}$ ). Matched anatomical T1-weighted images also were acquired for region of interest (ROI) placement.

To quantify craving levels, a visual analog desire for cocaine scale was administered prior to and after scanning, to determine change scores, as described previously (Maas et al, 1998). All fMRI data were motion-corrected before analysis (Maas et al, 1997). One image slice, containing the bulk of cerebellar lobule VIII, was selected for vermis ROI placements. Three ROIs (Figure 1a and b) encompassing anterior vermis (AV: lobules II-III), posterior-superior vermis (PSV: lobules $\mathrm{V}-\mathrm{VI}$ ), and posterior-inferior vermis (PIV: lobules VIII-IX) were selected to compare axonal 

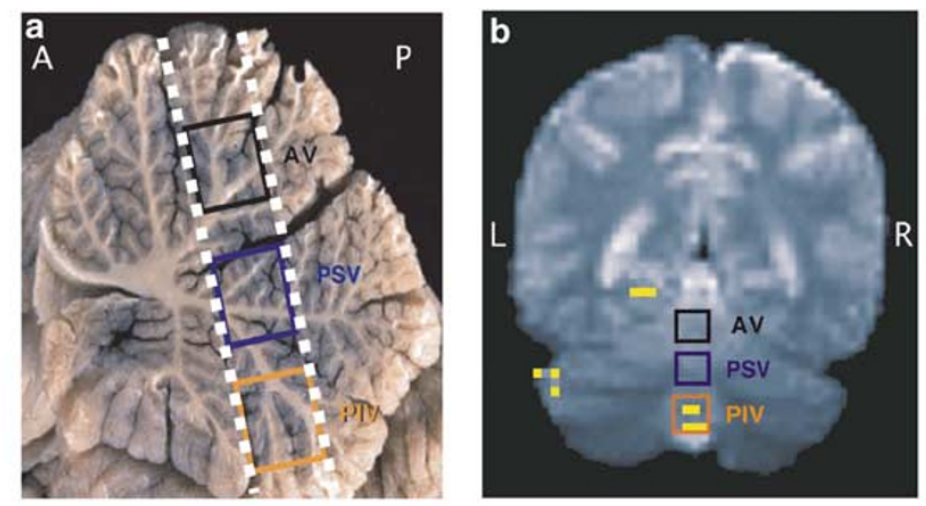

C

d
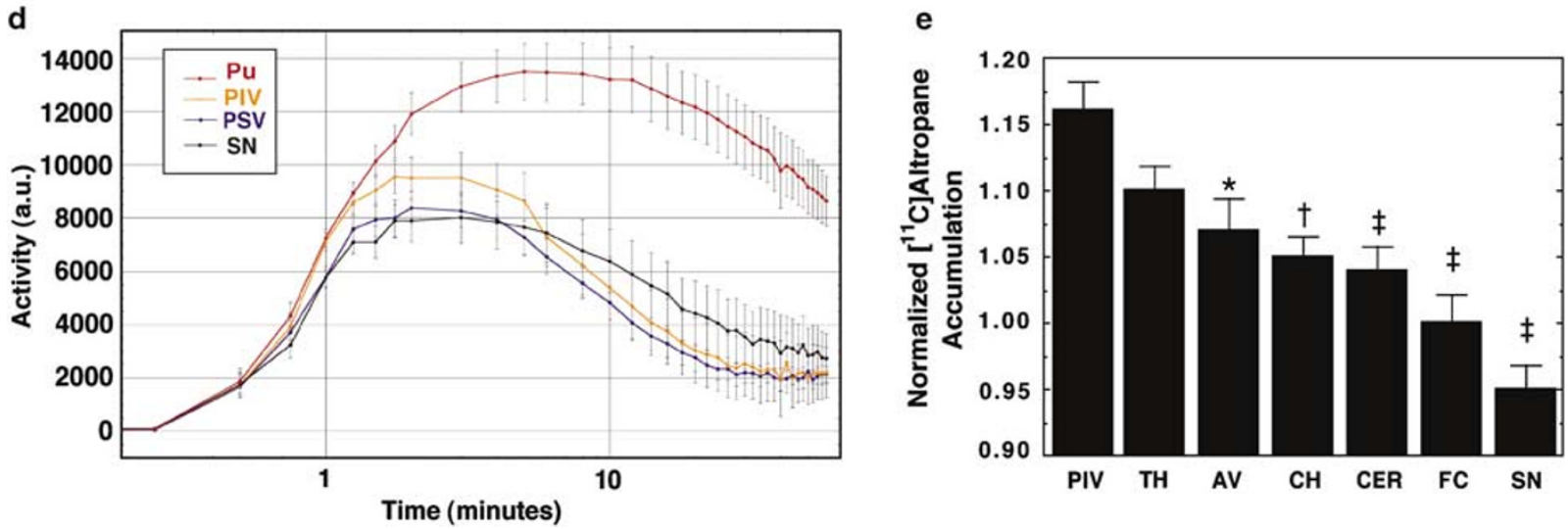

Figure I BOLD $\mathrm{fMRI}$ activation of and [ ' $\mathrm{C}$ ]altropane accumulation in vermis. (a) Midsagittal vermis gross anatomy section overlaid with the approximate position of the coronal oblique $\mathrm{PMRI}$ acquisition slice (A, anterior; $\mathrm{P}$, posterior; $\mathrm{L}$, left; $\mathrm{R}$, right). The black, blue, and orange box overlays on panels a and $b$ represent the AV, PSV, and PIV, respectively. (b) BOLD activation map from a single cocaine subject overlaid on an oblique image. Yellow pixels represent activation foci at the $P=9 \times 10^{-12}$ statistical significance level. (c) PIV activation time course for pixels within the PIV box on panel b; bluish gray and green epochs indicate neutral and cocaine cue periods, respectively. (d) [ ${ }^{\prime \prime}$ C]altropane PET time-activity curves. Shown are mean (SE) activity levels (a.u. arbitrary units) from II healthy subjects in putamen (Pu), posterior-inferior vermis (PIV), posterior-superior vermis (PSV), and substantia nigra (SN). (e) Normalized regional [ ' $\mathrm{C}$ ]altropane accumulation during the initial $6 \mathrm{~min}$ after ligand infusion. Shown are means (SE) in various brain regions, normalized to PSV accumulation. Posterior-inferior vermis (PIV); thalamus (TH): anterior vermis (AV); cerebellar hemispheres (CH); whole cerebellar slice (axial aspect) (CER); frontal cortex (FC); substantia nigra (SN). Post hoc tests with Bonferroni multiple comparisons correction for significant difference from PIV: *P<0.05; ${ }^{\dagger} P<0.0$ I; ${ }^{\ddagger} P \leqslant 0.005$. In all panels, regions with bilateral representations were averaged into single data values.

DAT-IR-enriched zones (AV and PIV) to the DAT-IR-poor zone (PSV). These ROIs were identified on matched anatomical MR images and mapped to the midcerebellar fMRI slice by a single rater blind to subject identities. BOLD fMRI activation was estimated as percent change in the mean ROI intensities measured between neutral and cocaine-cue fMRI segments and as spatial activation extent (fraction of regional pixels exceeding an $r=0.30$ activation threshold, as noted previously (Maas et al, 1998)). We established good inter-rater reliability for both activation measures (Maas et al, 1998).

\section{$\left[{ }^{11} \mathrm{C}\right]$ altropane In Vivo PET}

PET with $\left[{ }^{11} \mathrm{C}\right]$ altropane was conducted in 11 healthy adults (two women) aged $23.9 \pm 0.9$ years old, who provided informed consent to participate in this study. Images were acquired using a HR + (CTI, Knoxville, TN) PET camera. Camera imaging parameters are in-plane and axial resolutions of 4.5-mm FWHM, with 63 contiguous slices of 2.5$\mathrm{mm}$ separation. Images were acquired in $3 \mathrm{D}$ mode and reconstructed using an iterative algorithm to an in-plane resolution of $4.5-\mathrm{mm}$ FWHM. Photon attenuation measurements were made with ${ }^{68} \mathrm{Ge}$ rotating pin sources. For each scan, $\sim 5 \mathrm{mCi}$ of $\left[{ }^{11} \mathrm{C}\right]$ altropane was injected intravenously over $30 \mathrm{~s}$. Dynamic image collection started at infusion and images were acquired in 15-s frames (initial $2 \mathrm{~min}$ ), in 1min frames (next $4 \mathrm{~min}$ ), and in 2-min frames (remaining $54 \mathrm{~min}$ ). All projection data were corrected for detector response nonuniformity, dead time, random coincidences, and scattered radiation.

The initial 11 volumes acquired immediately after injection of the $\left[{ }^{11} \mathrm{C}\right]$ altropane bolus were summed to create blood flow images on which ROIs were manually traced using an in-house tool written for AVS (Advanced Visual Systems Inc., Waltham, MA). ROIs were positioned bilaterally on frontal cortex, thalamus, substantia nigra, and cerebellar hemispheres. ROIs also were traced within the highest intensity core of the putamen bilaterally on axial slices. For vermis, three ROIs were sampled in the sagittal plane within AV, PSV, and PIV. The complete set of ROIs was replicated on summed volumes (14-31) to represent bound $\left[{ }^{11} \mathrm{C}\right]$ altropane. 
Relative regional $\left[{ }^{11} \mathrm{C}\right]$ altropane accumulation levels were calculated over the first 6 min after ligand infusion as quotients of summed activity within each ROI, divided by PSV summed activity. The referent PSV reportedly is DATIR devoid (Melchitzky and Lewis, 2000). For regions with bilateral representations, ROI values were averaged across hemispheres. Relative activity levels were analyzed with ANOVA to detect a regional difference in $\left[{ }^{11} \mathrm{C}\right]$ altropane accumulation. The putamen, which contains high DAT levels, was excluded from all statistical analyses, so that it did not bias our global analyses in favor of finding regional differences in $\left[{ }^{10} \mathrm{C}\right]$ altropane accumulation. Post hoc tests were conducted using a Bonferroni correction for multiple comparisons.

\section{$\left[{ }^{3} \mathrm{H}\right] \mathrm{CFT}$ In Vitro Receptor Autoradiography}

Cerebellar vermis tissue blocks from two healthy women (pathologically confirmed) were obtained from the Harvard Brain Tissue Resource Center at McLean Hospital and stored until sectioning at $-80^{\circ} \mathrm{C}$. Subject age, post-mortem index, and time interval between death and the autoradiography study were $60 \pm 2.8$ years, $19.3 \pm 7.1 \mathrm{~h}$, and $1.8 \pm 0.3$ years, respectively. Autoradiography was conducted as described (Kaufman et al, 1991). Vermis tissue blocks were sectioned $(20 \mu \mathrm{m}$ thickness) sagittally on a cryostat at $-18^{\circ} \mathrm{C}$. Tissue sections were thaw-mounted onto Adhesion Superfrost Plus microscope slides (Brain Research Laboratories, Newton, MA) and stored at $-80^{\circ} \mathrm{C}$. Tissue sections were equilibrated at $0^{\circ} \mathrm{C} 12 \mathrm{~h}$ prior to autoradiography studies. Six sections per brain were preincubated for $20 \mathrm{~min}$ in Tris buffer $(50 \mathrm{mM}$ Tris- $\mathrm{HCl}$ containing $100 \mathrm{mM} \mathrm{NaCl}$, $\mathrm{pH} 7.4$ at $4{ }^{\circ} \mathrm{C}$ ), then incubated in triplicate for $2 \mathrm{~h}$ in buffer containing tracer $(10 \mathrm{nM})$ concentrations of $\left[{ }^{3} \mathrm{H}\right] \mathrm{CFT}$ $\left(\left[{ }^{3} \mathrm{H}\right]\right.$ WIN 35428 , spec. act.: $81.3 \mathrm{Ci} / \mathrm{mmol}$, Dupont-New England Nuclear, Boston, MA) to measure total binding, or with $10 \mathrm{nM}\left[{ }^{3} \mathrm{H}\right] \mathrm{CFT}$ and $30 \mu \mathrm{M}(-)$-cocaine hydrochloride to measure nonspecific binding, washed with two 1-min rinses in ice-cold buffer, dipped rapidly in ice-cold distilled water, and dried with chilled desiccated air. Tissue sections and autoradiographic standards $\left(\left[{ }^{3} \mathrm{H}\right]\right.$ Microscales, Amersham Biosciences Corp., Piscataway, NJ) were apposed to autoradiographic film (Hyperfilm- $\left[{ }^{3} \mathrm{H}\right]$, Amersham Biosciences Corp., Piscataway, NJ) for 10 weeks at $4^{\circ} \mathrm{C}$. Films were developed at room temperature using Kodak D-19 developer $(5 \mathrm{~min})$, rinsed in water for $30 \mathrm{~s}$, fixed in Kodak Rapid Fix for $5 \mathrm{~min}$, and washed for $20 \mathrm{~min}$. Films were dipped in Kodak Photoflo and hung to air dry. Densitometric data were acquired from DAT-IR-enriched lobule VIII and DAT-IR-poor lobule VI, as well as from whole vermis and vermis white matter, using the MCID analysis system (St Catharines, Ont.). Densities are expressed as regional ratios and statistical analyses were conducted using one sample $t$-tests.

\section{RESULTS}

\section{BOLD fMRI Studies}

Cocaine but not comparison subjects reported increased desire for cocaine following cocaine cue presentation. Mean desire ratings increased by 2.2 ( $0-10$ scale) arbitrary units
$(\mathrm{SD}=2.7, t=2.7, P<0.03)$. There was a group difference in vermis BOLD activation $\left(\mathrm{F}_{1,16}=4.95, P=0.04\right)$ with cocaine subjects exhibiting higher mean percent increases $(0.48 \%$ magnitude difference) than comparison subjects. Within vermis, BOLD activation magnitudes differed by region $\left(\mathrm{F}_{2,32}=7.51, P=0.002\right)$; post hoc Scheffe tests indicated greater BOLD activations in AV and PIV than in PSV $(P<0.01)$. Mean BOLD activation spatial extent scores also were greater $\left(\mathrm{F}_{1,16}=7.17, P<0.02\right)$ and regional differences were identified $\left(\mathrm{F}_{2,32}=6.70, P=0.004\right)$ in cocaine subjects; post hoc Scheffe tests indicated greater spatial activation extent in PIV than PSV $(P<0.005)$. We found a marginal association between desire rating change score and BOLD activation increase in PIV $(R=0.713, P<0.02)$, though that finding was strongly influenced by an outlier case, which, when removed, eliminated statistical significance. Although we did not identify sex differences on these measures, our study was not adequately powered to test for an effect of sex, and thus we cannot rule in or out any effects of sex.

\section{Autoradiography and PET Imaging Studies}

$\left[{ }^{3} \mathrm{H}\right] \mathrm{CFT}$-specific binding levels approached background $(<10 \mathrm{pmol} / \mathrm{g}$ tissue equivalent $)$ throughout vermis gray matter (data not shown). Although $\left[{ }^{3} \mathrm{H}\right] \mathrm{CFT}$ binding in lobule VIII was higher than white matter levels $(108.7 \pm 0.4 \%, P<0.005$, one sample $t$-test), it was marginally lower than binding in either lobule VI (DAT-IR-poor) or in whole vermis $(95.3 \pm 3.7$ and $93.0 \pm 0.4 \%$, respectively, $P<0.02$, one sample $t$-test).

In PET imaging studies, high $\left[{ }^{11} \mathrm{C}\right]$ altropane accumulation levels were detected in putamen, as expected. At early time points following ligand administration, time-activity curves were suggestive of greater peak $\left[{ }^{11} \mathrm{C}\right]$ altropane accumulation in PIV than in all other areas but putamen (Figure 1d). There was a regional difference in normalized ligand accumulation $\left(\mathrm{F}_{6,76}=12.2, P<0.001\right.$, excluding putamen). Post hoc testing with Bonferroni correction for multiple comparisons indicated that PIV $\left[{ }^{11} \mathrm{C}\right]$ altropane accumulation was greater than in substantia nigra, frontal cortex, and all other cerebellar regions (Figure 1e). Thalamic $\left[{ }^{11} \mathrm{C}\right]$ altropane accumulation was equivalent to that in PIV. We were unable to detect appreciable PIV accumulation using binding potential analysis (data not shown), though that method may be less sensitive for detecting transient ligand accumulations in regions containing low specific binding densities.

\section{DISCUSSION}

These data document cocaine cue-induced cerebellar vermis BOLD fMRI activation in cocaine users and selective PIV $\left[{ }^{11} \mathrm{C}\right]$ altropane accumulation in healthy subjects at early time points following ligand administration. Consistent with our a priori hypotheses, BOLD activation occurred only in AV and PIV, regions containing axonal DAT-IR (Melchitzky and Lewis, 2000). Group differences (cocaine users $v s$ controls) in BOLD activation magnitudes (0.62 and $0.37 \%$ in AV and PIV, respectively) were substantially larger than those we reported previously in the same subjects in anterior cingulate $(0.29 \%)$ and left dorsolateral prefrontal 
cortex $(0.20 \%)$ (Maas et al, 1998). This may indicate that cocaine cue exposure induces greater neuronal activation in vermis than in forebrain structures (Kim et al, 2004). Alternatively, the larger apparent BOLD signal response in vermis ROIs could have resulted from less partial voluming (and less BOLD activation dilution per volume tissue) for discrete vermis lobules.

Since we observed significant activation in vermis lobules VIII-IX, which also are activated by smooth pursuit oculomotor movements (Tanabe et al, 2002), and since such movements were necessary to view the cocaine cue program, smooth pursuit eye motion may have contributed to BOLD responses. However, smooth pursuit eye movements occurred in all subjects but lobules VIII-IX were activated only in cocaine subjects. This suggests that cocaine-related visual stimuli, salient only to cocaine users, induced either new activity or a potentiated form of smooth pursuit activation in lobules VIII-IX in cocaine abusers. Vermis lobules VII and VIII process auditory information (Brodal, 1980) and the combination of salient auditory and visual cocaine-related cues may have contributed to lobule VIII-IX activation. As there were no other overt motor requirements in our paradigm, we interpret these findings to suggest that salient polysensory qualities of the cue paradigm selectively activated portions of the vermis.

It also is conceivable that the vermis BOLD activations we identified in cocaine users represent early sensory processing of visual and auditory stimuli presented in the cocaine cue paradigm. In this regard, neurophysiology studies in cats noted vermis lobule VIII activation in response to auditory-visual stimuli (Snider and Stowell, 1944). PET blood flow studies in healthy humans documented anterior and posterior vermis activations during early sensory recognition of complex auditory and visual stimuli (Penhune et al, 1998). These regions were proposed to be part of a supramodal sensory timing apparatus that computes temporal parameters of incoming sensory stimuli to support timed motor responses (Penhune et al, 1998). While visual and/or auditory sensory stimuli might induce early vermis activations independent of DAT activity, the localization of significant DAT-IR in this region in primates implies that dopaminergic mechanisms linked with reward could coexist and interact with such early sensory processing circuits. From these findings, we conclude that axonal DAT-IR-enriched vermis lobules are activated by cocainerelated cues. The vermis also is activated during stimulant expectancy (Volkow et al, 2003) and in alcoholics during alcohol odor cue-induced craving (Schneider et al, 2001), implying that it may generally activate in response to drugassociated stimuli in drug abusing cohorts.

Our PET findings suggest that at early time points after ligand administration $\left[{ }^{11} \mathrm{C}\right]$ altropane accumulated at higher levels in PIV than in substantia nigra, frontal lobe, and other cerebellar areas. This finding is consistent with the report of DAT-IR enrichment in this area (Melchitzky and Lewis, 2000). PET time-activity curves indicated that PIV $\left[{ }^{11} \mathrm{C}\right]$ altropane washout was more rapid than in putamen or substantia nigra, suggesting different ligand kinetics in PIV $v s$ putamen and substantia nigra. It is unlikely that the excess PIV $\left[{ }^{11} \mathrm{C}\right]$ altropane accumulation is solely the result of blood flow differences since PET blood flow data from healthy adults indicate mismatches between cerebellar blood flow patterns, which are higher in cerebellar hemispheres than vermis and homogenous within vermis (Ouchi et al, 2001; Ito et al, 2003) and $\left[{ }^{11} \mathrm{C}\right]$ altropane accumulation, which was lowest in cerebellar hemispheres and was heterogeneous within vermis. Although it is possible that excess $\left[{ }^{11} \mathrm{C}\right]$ altropane accumulation in PIV represented labeling of other sites (see below), a parsimonious conclusion is that DAT may be present in the DAT-IR-enriched PIV and that this region may be a proximate site of action of cocaine, methylphenidate, and other drugs that interact with the dopamine transporter.

Our human post-mortem autoradiography studies were unable to detect vermis-specific $\left[{ }^{3} \mathrm{H}\right] \mathrm{CFT}$ binding. Thus, our autoradiography data appear to conflict both with our own PET imaging data and with prior DAT-IR findings (Melchitzky and Lewis, 2000). The lower DAT affinity and selectivity of CFT vs altropane (Madras et al, 1998), and the lower affinity of radioreceptor ligands (nanomolar range) vs immunohistochemical ligands (subnanomolar range), may in part explain why we failed to detect specific $\left[{ }^{3} \mathrm{H}\right] \mathrm{CFT}$ autoradiography binding in vermis, when binding was detected with other DAT-selective ligands. Two additional factors may have contributed to our inability to detect specific $\left[{ }^{3} \mathrm{H}\right] \mathrm{CFT}$ binding with autoradiography: our studies were conducted in the post-mortem state in tissues from elderly subjects. DAT radioligand binding declines postmortem by up to $35 \%$ after 5 or more hours of post-mortem time (Patel et al, 1993) and the post-mortem interval for tissues used in this study averaged $19.3 \mathrm{~h}$. In addition, a number of studies have shown that DAT radioligandbinding density declines with age in healthy subjects (see, for example, Kaufman and Madras, 1993; Volkow et al, 1994; van Dyck et al, 1995). The 3.5-decade age difference between our PET and autoradiography subjects (averaging 25 and 60 years old, respectively) might have resulted in a significant depletion of DAT activity (using an $8 \%$ per decade decline in DAT activity, van Dyck et al, 1995). Together, post-mortem time and aging effects could result in significant losses of functional DAT, comparable to the differences reported between cryopreserved human caudate nucleus and fresh rat striatum (Eshleman et al, 2001). Thus, if $\left[{ }^{11} \mathrm{C}\right]$ altropane accumulation in the vermis indeed reflects DAT binding, and if vermis and striatal DAT losses are parallel with post-mortem factors and age, then conceivably, detection of specific $\left[{ }^{3} \mathrm{H}\right] \mathrm{CFT}$ binding to vermis DAT would be severely compromised. This could explain our negative autoradiography findings. Recent rodent studies suggest that the age-associated decline in functional DAT results not from loss of DAT protein but from reduced functional DAT expression in the plasma membrane (Salvatore et al, 2003). Accordingly, in healthy subjects at any age, DAT may be easier to detect with immunohistochemical than with radioreceptor methods. This also means that a proportion of vermis DAT-IR detected in prior studies may not represent functional DAT protein.

Interestingly, thalamic $\left[{ }^{11} \mathrm{C}\right]$ altropane accumulation was statistically equivalent to that in PIV (Figure 1e). DAT-IR has been reported in thalamus (Melchitzky and Lewis, 2001) and thalamic $\left[{ }^{11} \mathrm{C}\right]$ cocaine accumulation was proposed to reflect DAT binding (Telang et al, 1999). Moreover, a very recent report described a significant dopaminergic innervation of the primate thalamus including a confirmation of 
widespread DAT-IR localization (Sanchez-Gonzalez et al, 2005). Thus, thalamic $\left[{ }^{11} \mathrm{C}\right]$ altropane accumulation may reflect DAT-binding sites. Clearly, additional pharmacological studies are required in PIV and thalamus to more precisely characterize the nature of cocaine congener accumulation in these areas. This is important because cocaine has comparable affinity for dopamine, norepinephrine (NET), and serotonin transporters, and cocaine's effects may be mediated in some regions via interactions with sites other than DAT. For example, frontal lobe dopamine uptake occurs primarily via NET activity (Moron et al, 2002). NET is present in cerebellum including vermis (Ding et al, 2003). Accordingly, some cerebellar regions containing NET might mediate effects of cocaine and its cues. While the present data do not identify vermis substrates activated by cocaine or its cues, they suggest that the PIV contains elements that may mediate or participate in both effects.

\section{Cerebellar Connectivity to Dopamine Circuitry}

Our findings suggesting that parts of the vermis mediate effects of cocaine and its cues are consistent with prior data documenting vermis connections to dopamine cell body regions in the ventral tegmental area (VTA) and substantia nigra (Snider et al, 1976). In addition, the VTA projects to cerebellum (Ikai et al, 1992) implying the presence of a reciprocal midbrain to cerebellum circuit. A subset of VTA efferents to cerebellum appears to be dopaminergic (Ikai et al, 1992) and some of those projections could be a target for DAT-IR labeling and contain DAT-binding sites.

Interestingly, in rodents, a proportion of VTA efferents bifurcates, sending projections both to cerebellum and either prelimbic/anterior cingulate or piriform-entorhinal cortex; such projections are segregated from VTA connections to subcortical (including limbic subcircuitry) structures (Ikai et al, 1994). Those bifurcating projections, together with cerebellar efferents to VTA (Snider et al, 1976), could form a separate circuit connecting cerebellum to frontal and temporal lobes independent of ascending thalamic (Middleton and Strick, 2001) and descending pontine (Schmahmann and Pandya, 1997) relays. Such circuitry could be a basis for forebrain dopamine turnover changes induced by vermis lesions (Snider and Snider, 1977), could account for our finding of vermis activation in cocaine abusers by cocaine-related cues, and could explain why the cerebellum tends to coactivate with frontal lobes during some cognitive tasks (see below).

\section{Reward Circuitry, The Cerebellum, and Incentive-Related Behaviors}

The reward circuitry has been proposed to participate as a shared pathway for processing drug and nondrug rewards (Garavan et al, 2000) and aversive stimuli (Becerra et al, 2001). Vermis activation also occurs in response to nondrug rewards or their anticipation (Rogers et al, 1999; Kunig et al, 2000; Martin-Solch et al, 2001; Knutson et al, 2003), painful or aversive stimuli or their anticipation (Paradiso et al, 1999; Casey et al, 2000; Becerra et al, 2001), and interoceptive stimuli triggered by vegetative regulatory functions including thirst (Egan et al, 2003), hunger
(Tataranni et al, 1999), and respiratory stress (Evans et al, 2002). Together, those findings are consistent with the suggestion that the cerebellum and the vermis process multimodal sensory inputs to influence cortical excitability and enhance motor sequence learning and execution (Molinari et al, 2002).

That multimodal sensory processing function may be a form of or closely related to selective attention, as vermis participates both in attentional processes linked to motor responses (Allen et al, 1997) and in response reassignment, which involves context-dependent changes in sensorimotor sets to facilitate motor outputs (Bischoff-Grethe et al, 2002). These capacities may be very important in drug dependence (and its treatment) since a 'hyperattentive state' with regard to salient drug-related stimuli may underlie drug craving and relapse (Franken, 2003). Vermis activation in response to cocaine-related cues (present study) and in response to alcohol odor cues (Schneider et al, 2001) may indicate that it is involved in 'hyperattentive states.' This could be significant as vermis also is involved in later stages of voluntary movement planning (Hülsmann et al, 2003) and thus is positioned to strongly influence behavioral output (Cotterill, 2001).

Of course, the vermis and other cerebellar areas do not function in isolation but rather coordinate task processing duties with other forebrain structures via cerebello-thalamo-cortical (Middleton and Strick, 2001) and corticoponto-cerebellar streams (Schmahmann and Pandya, 1997), and perhaps also via VTA circuitry (see above). The fronto-cerebellar interplay seems to be dynamic in nature and normally is dominated by frontal structures (Smith and Jonides, 1997; Gould et al, 2003), with cerebellar structures playing a supporting role. However, in addiction disorders, in which the frontal lobes are known to be compromised (Goldstein and Volkow, 2002), cerebellar (and vermis) activity appears to increase to support several tasks involving frontal lobe function including monetary reward response (Martin-Soelch et al, 2001), response inhibition (Hester and Garavan, 2004), and working memory (Desmond et al, 2003). Vermis activation also occurs during reward tasks in Parkinson's and in attention deficit hyperactivity disorder patients, but not in comparison subjects (Ernst et al, 2003; Goerendt et al, 2004; Kunig et al, 2000). In addition, increased cerebellar (and vermis) activation occur to support working memory function in frontotemporal dementia, Parkinson's Disease, and schizophrenia, (Mentis et al, 2003; Meyer-Lindenberg et al, 2001; Rombouts et al, 2003). Thus, several domains of frontal lobe function pertinent to addiction-related behaviors appear to be supported by cerebellum and vermis. Along with the present findings, these observations suggest that the vermis plays a central role in organizing sensory inputs and planning motor responses to rewarding and other incentiverelated stimuli, and that its role in modulating these responses may increase when the frontal lobes are compromised by disease or chronic drug use.

\section{Limitations}

These findings must be interpreted in light of several limitations. First, our fMRI data were acquired with older technology and analyzed retrospectively, after learning that 
DAT-IR is present in primate vermis (Melchitzky and Lewis, 2000). Thus, fMRI acquisition parameters were not optimized for detecting cerebellar activations, and in particular, for activations localized to specific vermis lobules. For this reason, we believe that the BOLD activation magnitudes we identified may be very conservative estimates of localized vermis responses to cocaine-related cues. Second, the ligand we used for PET-imaging studies, $\left[{ }^{11} \mathrm{C}\right]$ altropane, exhibits fast washout kinetic properties. Thus, it probably is not optimal for detecting DAT in regions with low DAT densities. Indeed, binding potential analysis was unable to identify DAT binding in PIV. Yet, we found statistically significant normalized $\left[{ }^{11} \mathrm{C}\right]$ altropane accumulation differences within vermis and cerebellum (when referenced to the DAT-devoid PSV) that cannot be attributed to blood flow differences (Ouchi et al, 2001; Ito et al, 2003), suggesting the presence of DAT binding in PIV. Third, we were unable to detect specific $\left[{ }^{3} \mathrm{H}\right] \mathrm{CFT}$ binding in vermis lobule VIII suggesting some discrepancy between $\left[{ }^{3} \mathrm{H}\right] \mathrm{CFT}$ and both DAT-IR and $\left[{ }^{11} \mathrm{C}\right]$ altropane labeling. As noted above, this discrepancy could be related to differential kinetics and pharmacological specificity for these ligands (Madras et al, 1998; Fischman et al, 2001) as well as from age and post-mortem reductions in functional DAT expression (Patel et al, 1993; Salvatore et al, 2003). Notwithstanding these limitations, we believe the present findings support the concept that the cerebellar vermis is involved in mediating cocaine-related behaviors. We also believe that these findings warrant further studies to better characterize cerebellar and vermis roles in cocaine- and other incentive-related behaviors and to identify vermis substrates mediating the effects noted presently.

\section{ACKNOWLEDGEMENTS}

We thank the National Institute on Drug Abuse (DA016222 (CMA), DA16746 (CMA), DA017324 (MJK), DA009448 (PFR), DA03994 (SEL), DA014178 (PFR), DA014674 (MJK), DA015116 (PFR), DA14013 (BdeBF), DA00343 (SEL), DA015305 (BKM), DA006303 (BKM)), and RR000168 (BKM) for supporting these studies, the Harvard Brain Tissue Resource Center, supported in part by PHS Grant $\mathrm{MH} / \mathrm{NS} 31862$, for donating human post-mortem cerebellar vermis tissue, the Whitaker Foundation, the John and Virginia B Taplin Endowment Fund, and the Dr Ralph and Marian C Falk Medical Research Trust. We thank Anne Smith, RTR, Eileen Connolly, RTR, Veronica Rogers, Sarah Daniels, and Thellea Kukes for assistance in data collection. Portions of these data were previously published in abstract form at the 64th and 67th Annual Scientific Meetings of the College on Problems of Drug Dependence, Quebec City, Quebec, June 2002 and Orlando, FL, 2005, respectively.

\section{REFERENCES}

Allen G, Buxton RB, Wong EC, Courchesne E (1997). Attentional activation of the cerebellum independent of motor involvement. Science 275: 1940-1943.

Ball GG, Micco Jr DJ, Berntson GG (1974). Cerebellar stimulation in the rat: complex stimulation-bound oral behaviors and selfstimulation. Physiol Behav 13: 123-127.
Becerra L, Breiter HC, Wise R, Gonzalez RG, Borsook D (2001). Reward circuitry activation by noxious thermal stimuli. Neuron 32: 927-946.

Bischoff-Grethe A, Ivry RB, Grafton ST (2002). Cerebellar involvement in response reassignment rather than attention. J Neurosci 22: 546-553.

Bonson KR, Grant SJ, Contoreggi CS, Links JM, Metcalfe J, Weyl HL et al (2002). Neural systems and cue-induced cocaine craving. Neuropsychopharmacology 26: 376-386.

Brodal P (1980). The projection from the nucleus reticularis tegmenti pontis to the cerebellum in the rhesus monkey. Exp Brain Res 38: 29-36.

Casey KL, Svensson P, Morrow TJ, Raz J, Jone C, Minoshima S (2000). Selective opiate modulation of nociceptive processing in the human brain. J Neurophysiol 84: 525-533.

Childress AR, Mozley PD, McElgin W, Fitzgerald J, Reivich M, O’Brien CP (1999). Limbic activation during cue-induced cocaine craving. Am J Psychiatr 156: 11-18.

Cotterill RM (2001). Cooperation of the basal ganglia, cerebellum, sensory cerebrum and hippocampus: possible implications for cognition, consciousness, intelligence and creativity. Prog Neurobiol 64: 1-33.

Desmond JE, Chen SH, DeRosa E, Pryor MR, Pfefferbaum A, Sullivan EV (2003). Increased frontocerebellar activation in alcoholics during verbal working memory: an fMRI study. Neuroimage 19: 1510-1520.

Ding YS, Lin KS, Garza V, Carter P, Alexoff D, Logan J et al (2003). Evaluation of a new norepinephrine transporter PET ligand in baboons, both in brain and peripheral organs. Synapse 50: 345-352.

Domino EF, Minoshima S, Guthrie S, Ohl L, Ni L, Koeppe RA et al (2000). Nicotine effects on regional cerebral blood flow in awake, resting tobacco smokers. Synapse 38: 313-321.

Egan G, Silk T, Zamarripa F, Williams J, Federico P, Cunnington R et al (2003). Neural correlates of the emergence of consciousness of thirst. Proc Natl Acad Sci USA 100: 15241-15246.

Ernst M, Kimes AS, London ED, Matochik JA, Eldreth D, Tata S et al (2003). Neural substrates of decision making in adults with attention deficit hyperactivity disorder. Am J Psychiatr 160: 1061-1070.

Eshleman AJ, Wolfrum K, Mash DC, Christensen K, Janowsky A (2001). Drug interactions with the dopamine transporter in cryopreserved human caudate. J Pharmacol Exp Ther 296: 442-449.

Evans KC, Banzett RB, Adams L, McKay L, Frackowiak RS, Corfield DR (2002). BOLD fMRI identifies limbic, paralimbic, and cerebellar activation during air hunger. J Neurophysiol 88: $1500-1511$.

Fischman AJ, Bonab AA, Babich JW, Livni E, Alpert NM, Meltzer PC et al (2001). [(11)C, (127)I] Altropane: a highly selective ligand for PET imaging of dopamine transporter sites. Synapse 39: $332-342$.

Franken IH (2003). Drug craving and addiction: integrating psychological and neuropsychopharmacological approaches. Prog Neuropsychopharmacol Biol Psychiatr 27: 563-579.

Garavan H, Pankiewicz J, Bloom A, Cho JK, Sperry L, Ross TJ et al (2000). Cue-induced cocaine craving: neuroanatomical specificity for drug users and drug stimuli. Am J Psychiatr 157: 1789-1798.

Ghatan PH, Ingvar M, Eriksson L, Stone-Elander S, Serrander M, Ekberg $\mathrm{K}$ et al (1998). Cerebral effects of nicotine during cognition in smokers and non-smokers. Psychopharmacology (Berlin) 136: 179-189.

Goerendt IK, Lawrence AD, Brooks DJ (2004). Reward processing in health and Parkinson's disease: neural organization and reorganization. Cereb Cortex 14: 73-80.

Goldstein RZ, Volkow ND (2002). Drug addiction and its underlying neurobiological basis: neuroimaging evidence for 
the involvement of the frontal cortex. Am J Psychiatr 159: 16421652.

Gould RL, Brown RG, Owen AM, ffytche DH, Howard RJ (2003). fMRI BOLD response to increasing task difficulty during successful paired associates learning. Neuroimage 20: 1006-1019.

Grant S, London ED, Newlin DB, Villemagne VL, Liu X, Contoreggi $C$ et al (1996). Activation of memory circuits during cue-elicited cocaine craving. Proc Natl Acad Sci USA 93: 12040-12045.

Hester R, Garavan H (2004). Executive dysfunction in cocaine addiction: evidence for discordant frontal, cingulate, and cerebellar activity. J Neurosci 24: 11017-11022.

Hülsmann E, Erb M, Grodd W (2003). From will to action: sequential cerebellar contributions to voluntary movement. Neuroimage 20: 1485-1492.

Hurley MJ, Mash DC, Jenner P (2003). Markers for dopaminergic neurotransmission in the cerebellum in normal individuals and patients with Parkinson's disease examined by RT-PCR. Eur J Neurosci 18: 2668-2672.

Ikai Y, Takada M, Mizuno N (1994). Single neurons in the ventral tegmental area that project to both the cerebral and cerebellar cortical areas by way of axon collaterals. Neuroscience 61: 925-934.

Ikai Y, Takada M, Shinonaga Y, Mizuno N (1992). Dopaminergic and non-dopaminergic neurons in the ventral tegmental area of the rat project, respectively, to the cerebellar cortex and deep cerebellar nuclei. Neuroscience 51: 719-728.

Ito H, Kanno I, Takahashi K, Ibaraki M, Miura S (2003). Regional distribution of human cerebral vascular mean transit time measured by positron emission tomography. Neuroimage 19: 1163-1169.

Kalivas PW, McFarland K (2003). Brain circuitry and the reinstatement of cocaine-seeking behavior. Psychopharmacology (Berlin) 168: 44-56.

Kaufman MJ, Madras BK (1993). $\left[{ }^{3} \mathrm{H}\right] \mathrm{CFT}$ ([ $\left.{ }^{3} \mathrm{H}\right]$ WIN 35428$)$ accumulation in dopamine regions of monkey brain: comparison of a mature and an aged monkey. Brain Res 611: 322-325.

Kaufman MJ, Spealman RD, Madras BK (1991). Distribution of cocaine recognition sites in monkey brain: I. In vitro autoradiography with $\left[{ }^{3} \mathrm{H}\right] \mathrm{CFT}$. Synapse 9: 177-187.

Kilts CD, Schweitzer JB, Quinn CK, Gross RE, Faber TL, Muhammad $\mathrm{F}$ et al (2001). Neural activity related to drug craving in cocaine addiction. Arch Gen Psychiatr 58: 334-341.

Kim DS, Ronen I, Olman C, Kim SG, Ugurbil K, Toth LJ (2004). Spatial relationship between neuronal activity and BOLD functional MRI. Neuroimage 21: 876-885.

Knutson B, Fong GW, Bennett SM, Adams CM, Hommer D (2003). A region of mesial prefrontal cortex tracks monetarily rewarding outcomes: characterization with rapid event-related fMRI. Neuroimage 18: 263-272.

Kunig G, Leenders KL, Martin-Solch C, Missimer J, Magyar S, Schultz W (2000). Reduced reward processing in the brains of Parkinsonian patients. Neuroreport 11: 3681-3687.

Logan CG, Grafton ST (1995). Functional anatomy of human eyeblink conditioning determined with regional cerebral glucose metabolism and positron-emission tomography. Proc Natl Acad Sci USA 92: 7500-7504.

London ED, Broussolle EP, Links JM, Wong DF, Cascella NG, Dannals RF et al (1990). Morphine-induced metabolic changes in human brain. Studies with positron emission tomography and [fluorine 18]fluorodeoxyglucose. Arch Gen Psychiatr 47: 73-81.

Maas LC, Frederick BD, Renshaw PF (1997). Decoupled automated rotational and translational registration for functional MRI time series data: the DART registration algorithm. Magn Reson Med 37: 131-139.

Maas LC, Lukas SE, Kaufman MJ, Weiss RD, Daniels SL, Rogers VW et al (1998). Functional magnetic resonance imaging of human brain activation during cue-induced cocaine craving. $\mathrm{Am}$ J Psychiatr 155: 124-126.
Madras BK, Meltzer PC, Liang AY, Elmaleh DR, Babich J, Fischman AJ (1998). Altropane, a SPECT or PET imaging probe for dopamine neurons: I. Dopamine transporter binding in primate brain. Synapse 29: 93-104.

Martin-Soelch C, Chevalley AF, Kunig G, Missimer J, Magyar S, Mino A et al (2001). Changes in reward-induced brain activation in opiate addicts. Eur J Neurosci 14: 1360-1368.

Martin-Solch C, Magyar S, Kunig G, Missimer J, Schultz W, Leenders KL (2001). Changes in brain activation associated with reward processing in smokers and nonsmokers. A positron emission tomography study. Exp Brain Res 139: 278-286.

Melchitzky DS, Lewis DA (2000). Tyrosine hydroxylase- and dopamine transporter-immunoreactive axons in the primate cerebellum. Evidence for a lobular- and laminar-specific dopamine innervation. Neuropsychopharmacology 22: 466-472.

Melchitzky DS, Lewis DA (2001). Dopamine transporter-immunoreactive axons in the mediodorsal thalamic nucleus of the macaque monkey. Neuroscience 103: 1033-1042.

Mentis MJ, Dhawan V, Nakamura T, Ghilardi MF, Feigin A, Edwards C et al (2003). Enhancement of brain activation during trial- and-error sequence learning in early PD. Neurology 60: 612-619.

Meyer-Lindenberg A, Poline JB, Kohn PD, Holt JL, Egan MF, Weinberger DR et al (2001). Evidence for abnormal cortical functional connectivity during working memory in schizophrenia. Am J Psychiatr 158: 1809-1817.

Middleton FA, Strick PL (2001). Cerebellar projections to the prefrontal cortex of the primate. J Neurosci 21: 700-712.

Molinari M, Filippini V, Leggio MG (2002). Neuronal plasticity of interrelated cerebellar and cortical networks. Neuroscience 111: 863-870.

Moron JA, Brockington A, Wise RA, Rocha BA, Hope BT (2002). Dopamine uptake through the norepinephrine transporter in brain regions with low levels of the dopamine transporter: evidence from knock-out mouse lines. J Neurosci 22: 389-395.

Mostofsky SH, Schafer JG, Abrams MT, Goldberg MC, Flower AA, Boyce A et al (2003). fMRI evidence that the neural basis of response inhibition is task-dependent. Brain Res Cogn Brain Res 17: $419-430$

Ouchi Y, Okada H, Yoshikawa E, Futatsubashi M, Nobezawa S (2001). Absolute changes in regional cerebral blood flow in association with upright posture in humans: an orthostatic PET study. J Nucl Med 42: 707-712.

Paradiso S, Johnson DL, Andreasen NC, O'Leary DS, Watkins GL, Ponto LL et al (1999). Cerebral blood flow changes associated with attribution of emotional valence to pleasant, unpleasant, and neutral visual stimuli in a PET study of normal subjects. Am J Psychiatr 156: 1618-1629.

Patel A, Uhl G, Kuhar MJ (1993). Species differences in dopamine transporters: postmortem changes and glycosylation differences. J Neurochem 61: 496-500.

Penhune VB, Zattore RJ, Evans AC (1998). Cerebellar contributions to motor timing: a PET study of auditory and visual rhythm reproduction. J Cogn Neurosci 10: 752-765.

Rogers RD, Owen AM, Middleton HC, Williams EJ, Pickard JD, Sahakian BJ et al (1999). Choosing between small, likely rewards and large, unlikely rewards activates inferior and orbital prefrontal cortex. J Neurosci 19: 9029-9038.

Rombouts SA, van Swieten JC, Pijnenburg YA, Goekoop R, Barkhof F, Scheltens P (2003). Loss of frontal fMRI activation in early frontotemporal dementia compared to early $\mathrm{AD}$. Neurology 60: 1904-1908.

Salvatore MF, Apparsundaram S, Gerhardt GA (2003). Decreased plasma membrane expression of striatal dopamine transporter in aging. Neurobiol Aging 24: 1147-1154.

Sanchez-Gonzalez MA, Garcia-Cabezas MA, Rico B, Cavada C (2005). The primate thalamus is a key target for brain dopamine. J Neurosci 25: 6076-6083. 
Schmahmann JD, Pandya DN (1997). Anatomic organization of the basilar pontine projections from prefrontal cortices in rhesus monkey. J Neurosci 17: 438-458.

Schneider F, Habel U, Wagner M, Franke P, Salloum JB, Shah NJ et al (2001). Subcortical correlates of craving in recently abstinent alcoholic patients. Am J Psychiatr 158: 1075-1083.

Sell LA, Morris J, Bearn J, Frackowiak RS, Friston KJ, Dolan RJ (1999). Activation of reward circuitry in human opiate addicts. Eur J Neurosci 11: 1042-1048.

Smith EE, Jonides J (1997). Working memory: a view from neuroimaging. Cognit Psychol 33: 5-42.

Snider RS, Maiti A, Snider SR (1976). Cerebellar pathways to ventral midbrain and nigra. Exp Neurol 53: 714-728.

Snider RS, Stowell A (1944). Receiving areas of the tactile, auditory, and visual systems in the cerebellum. J Neurophysiol 7: 331-357.

Snider SR, Snider RS (1977). Alterations in forebrain catecholamine metabolism produced by cerebellar lesions in the rat. J Neural Transm 40: 115-128.

Tanabe J, Tregellas J, Miller D, Ross RG, Freedman R (2002). Brain activation during smooth-pursuit eye movements. Neuroimage 17: 1315-1324.

Tataranni PA, Gautier JF, Chen K, Uecker A, Bandy D, Salbe AD et al (1999). Neuroanatomical correlates of hunger and satiation in humans using positron emission tomography. Proc Natl Acad Sci USA 96: 4569-4574.
Telang FW, Volkow ND, Levy A, Logan J, Fowler JS, Felder C et al (1999). Distribution of tracer levels of cocaine in the human brain as assessed with averaged $\left[{ }^{11} \mathrm{C}\right]$ cocaine images. Synapse 31 : 290-296.

van Dyck CH, Seibyl JP, Malison RT, Laruelle M, Wallace E, Zoghbi SS et al (1995). Age-related decline in striatal dopamine transporter binding with iodine-123-beta-CITSPECT. J Nucl Med 36: 1175-1181.

Volkow ND, Fowler JS, Wang GJ, Logan J, Schlyer D, MacGregor R et al (1994). Decreased dopamine transporters with age in health human subjects. Ann Neurol 36: 237-239.

Volkow ND, Gillespie H, Mullani N, Tancredi L, Grant C, Valentine A et al (1996). Brain glucose metabolism in chronic marijuana users at baseline and during marijuana intoxication. Psychiatr Res 67: 29-38.

Volkow ND, Mullani N, Gould L, Adler SS, Guynn RW, Overall JE et al (1988). Effects of acute alcohol intoxication on cerebral blood flow measured with PET. Psychiatr Res 24: 201-209.

Volkow ND, Wang GJ, Ma Y, Fowler JS, Zhu W, Maynard L et al (2003). Expectation enhances the regional brain metabolic and the reinforcing effects of stimulants in cocaine abusers. J Neurosci 23: 11461-11468.

Wang GJ, Volkow ND, Fowler JS, Cervany P, Hitzemann RJ, Pappas NR et al (1999). Regional brain metabolic activation during craving elicited by recall of previous drug experiences. Life Sci 64: 775-784. 